\title{
Prediction Method of Wax Deposition Rate in Crude Oil Pipeline Based on RBF Neural Network and Support Vector Machine
}

\author{
ZhangYu $^{1, \mathrm{a}}$, WangRuoyu ${ }^{1, \mathrm{~b}}$, WangXue ${ }^{1, \mathrm{c}}$ \\ ${ }^{1}$ College of Energy and Environmental Engineering, Shandong Huayu University of Technology, Dezhou, Shandong, China
}

\begin{abstract}
Wax-bearing crude oil will precipitate wax crystals in pipeline transportation, which will cause hidden dangers and affect the economic benefits of the pipeline. In order to study the complex wax deposition on the pipe wall and calculate the wax deposition under other conditions, this paper uses RBF neural network and support vector machine to predict the wax deposition data in Huachi operation area. The results show that the errors of the two methods meet the requirements. Because support vector machine can model and calculate finite samples, it is found that the accuracy of support vector machine is higher.
\end{abstract}

\section{Introduction}

Due to the wax crystallization of waxy crude oil in pipeline transportation, wax deposition layer is attached to the wall of the pipeline, and the pressure required for pipeline oil transportation is increased by reducing the cross-sectional area of pipeline flow, which affects the economic benefits of pipeline transportation ${ }^{[1]}$. When the wax layer is too thick or even plugs the pipeline, it may cause a condensate pipe accident. In addition, in the actual production and operation, the receiving and transmitting drums are usually set at the beginning and end of the pipeline, and the pig or pig ball is put in the pipeline. With the flow of crude oil, the wax crystals along the pipeline are cleaned ${ }^{[2]}$. The number of balls is proportional to the investment, so it is of great significance to master the wax deposition law of the pipeline and predict the wax deposition phenomenon according to the law, so as to scientifically plan the cycle of wax removal.

\section{Influencing factors of wax deposition rules in crude oil}

The mechanism of wax deposition is mainly divided into molecular diffusion, shear diffusion, Brownian diffusion, gravity sedimentation and other factors. The molecular diffusion mechanism is accepted by most scholars. The influencing factors of wax deposition rate include oil flow temperature in pipe, ambient temperature along the pipeline, temperature difference between oil flow and pipeline wall, crude oil flow rate, crude oil composition and deposition time ${ }^{[3]}$.

The annular wax deposition experiment has the characteristics of ensuring that the crude oil injection and transportation status of the experiment and the actual pipeline are consistent with the wax deposition in the pipeline. In this paper, seven relevant factors affecting wax deposition, including wall temperature, crude oil temperature, viscosity, flow rate, wall shear stress, wall temperature gradient and wax molecular concentration gradient at the wall, were selected as the input data for simulation, and thus the rate prediction model of wax deposition was established ${ }^{[4]}$.

\section{Structure principle of RBF neural network}

\subsection{Introduction of RBF neural network}

RBF(Radial Basis Function) is a kind of feedforward neural network. In 1988, Broomhead and Lowe introduced RBF into the design of neural network. The RBF neural network has good approximation performance and faster convergence speed for complex nonlinear functions. It is widely used in the field of data classification and prediction ${ }^{[5]}$.

\subsection{Structure principle of RBF neural network}

RBF neural network is divided into three layers : input layer, hidden layer and output layer. the role between layers is shown in Table 1, and the specific structure is shown in Fig 1.

Table1. Functions of each layer of RBF neural network

\begin{tabular}{|c|l|l|}
\hline Input layer & Signal source node & Transmission signal \\
\hline \multirow{3}{*}{ hidden layer } & $\begin{array}{l}\text { Local response } \\
\text { function, number of } \\
\text { nodes depending on } \\
\text { the needs of the } \\
\text { problem described }\end{array}$ & $\begin{array}{l}\text { Adjusting } \\
\text { parameters of } \\
\text { activation function } \\
\text { by nonlinear } \\
\text { optimization }\end{array}$ \\
\hline
\end{tabular}




\begin{tabular}{|l|l|l|}
\hline & & strategy \\
\hline & & $\begin{array}{l}\text { Adjusting linear } \\
\text { weight and } \\
\text { adopting linear } \\
\text { output layer } \\
\text { optimization } \\
\text { Response to input } \\
\text { strategy, the } \\
\text { learning speed is } \\
\text { faster. }\end{array}$ \\
\hline
\end{tabular}

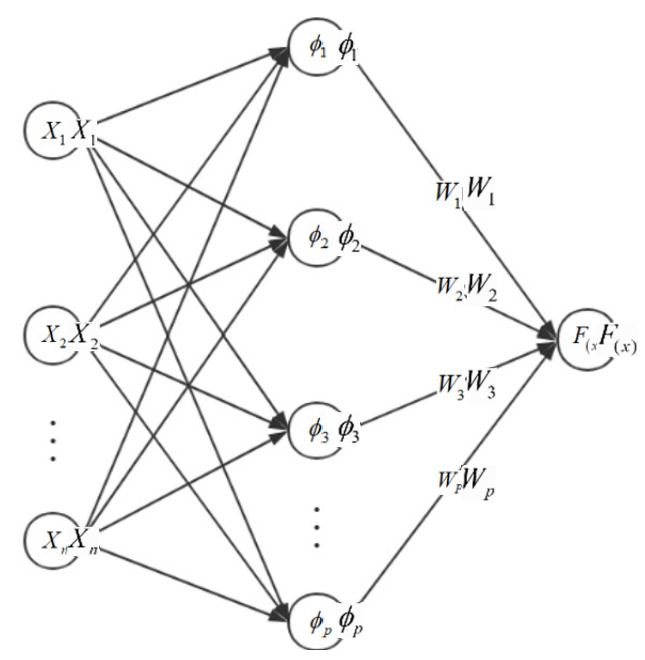

Fig 1. Structure diagram of RBF neural network

The 'base' of the hidden layer unit is composed of $\mathrm{RBF}$ to form the hidden layer space, connecting the two layers for nonlinear transformation. The sample vector is directly mapped to the hidden layer space through the input layer, and the low-dimensional input sample data are mapped to the high-dimensional space. Then, the output of the hidden layer is linearly weighted to obtain the output of the RBF network. The radial basis function in RBF neural network only generates local response and adjusts local important weights, which is greatly different from other neural networks with global response and global weight adjustment (e.g. BP neural network ).

\subsection{Practical calculation}

The experimental data obtained from Wang Xueliang' $\mathrm{s}^{[6]}$ experiments on crude oil in Huachi area, which are divided into 8 columns and 38 groups. Seven columns correspond to seven parameters, and the eighth column is the actual wax deposition rate.

According to the operation steps of RBF neural network, the data are first imported into Matlab, and the data are normalized by using the normalization command mapminmax $\left(\mathrm{a}^{\prime}, 0,1\right)$. The data model is then established using the newrb (X, T, GOAL, SPREAD, MN, DF) statements, and the parameters involved are selected in Table 2.

Table2. RBF neural network parameters

\begin{tabular}{|c|c|c|c|}
\hline GOAL & SPREAD & MN & DF \\
\hline 0.001 & 0.3 & 20 & 1 \\
\hline
\end{tabular}

The mean square error of the modeling and prediction results is shown in Fig. 2, and the absolute error and relative error are shown in Table 4.

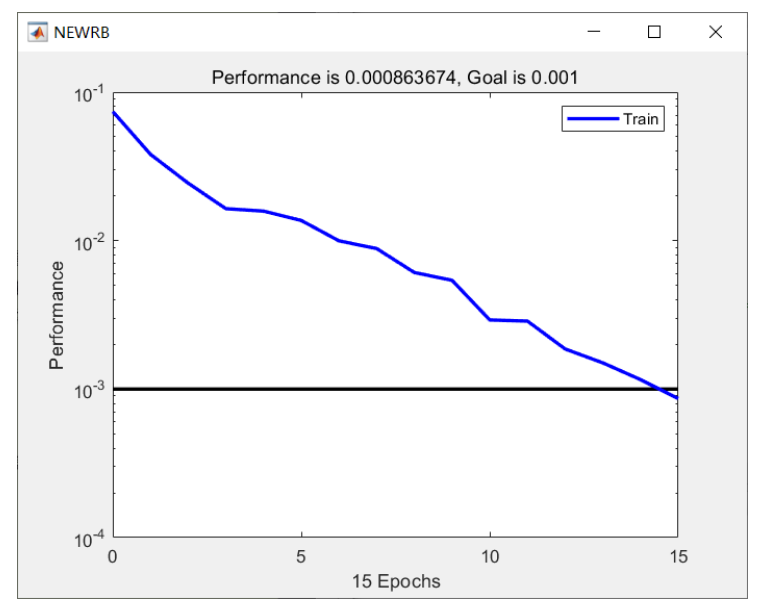

Fig 2. The variation curve of root mean square error of RBF neural network with the increase of neurons

Table3. RBF neural network prediction absolute error and relative error

\begin{tabular}{|c|c|c|c|c|}
\hline \multirow{2}{*}{ Number } & \multicolumn{2}{|c|}{$\begin{array}{c}\text { Wax deposition velocity } \\
\left(\mathrm{g} /\left(\mathrm{m}^{2} \mathrm{~h}\right)\right)\end{array}$} & $\begin{array}{c}\text { Relative } \\
\text { error } \\
(\%)\end{array}$ & $\begin{array}{c}\text { Absolute } \\
\text { error } \\
(\%)\end{array}$ \\
\cline { 2 - 3 } & $\begin{array}{c}\text { Experimental } \\
\text { value }\end{array}$ & $\begin{array}{c}\text { Predicted } \\
\text { value }\end{array}$ & & \\
\hline 1 & 8.66 & 9.17 & 5.89 & 0.51 \\
\hline 2 & 8.33 & 8.92 & 7.08 & 0.59 \\
\hline 3 & 8.12 & 8.65 & 6.53 & 0.53 \\
\hline 4 & 7.86 & 7.11 & 9.54 & 0.75 \\
\hline 5 & 18.09 & 16.04 & 11.33 & 2.05 \\
\hline 6 & 11.3 & 9.27 & 17.96 & 2.03 \\
\hline 7 & 22.46 & 14.96 & 33.39 & 7.50 \\
\hline 8 & 16.43 & 12.61 & 23.25 & 3.82 \\
\hline
\end{tabular}

From Table 3, it can be seen that the error size of the model trained by RBF neural network for the calculation of the eight groups of data in the prediction group is quite different. The maximum relative error is $33.39 \%$, the minimum relative error is $5.89 \%$, and the average relative error is $14.37 \%$. The error size is acceptable. The model has the feasibility of predicting wax deposition rate.

In this paper, the number of experimental data is limited. Based on the characteristics of neural network, the amount of data is proportional to the prediction accuracy ${ }^{[7]}$. Due to the long cycle of the single group of wax deposition pipeline experiments, and the systematic error of the loop experimental device, the experimental group is set too closely, which will blur the difference in experimental values. To solve this problem, support vector machine is introduced to predict wax deposition rate.

\section{Prediction of wax deposition rate based on support vector machine}

\subsection{Introduction to Support Vector Machine}

Support Vector Machine (SVM) is a machine learning 
method based on statistical learning theory $\mathrm{VC}$ dimension theory and structural risk minimization principle. It has advantages in dealing with many sample finite and nonlinear problems. In addition, support vector machine can greatly overcome the 'curse of dimensionality', which increases exponentially with the increase of dimension when it comes to vector computation.

\subsection{Structural Principle of Support Vector Machine}

The support vector machine structure is shown in Fig 3.

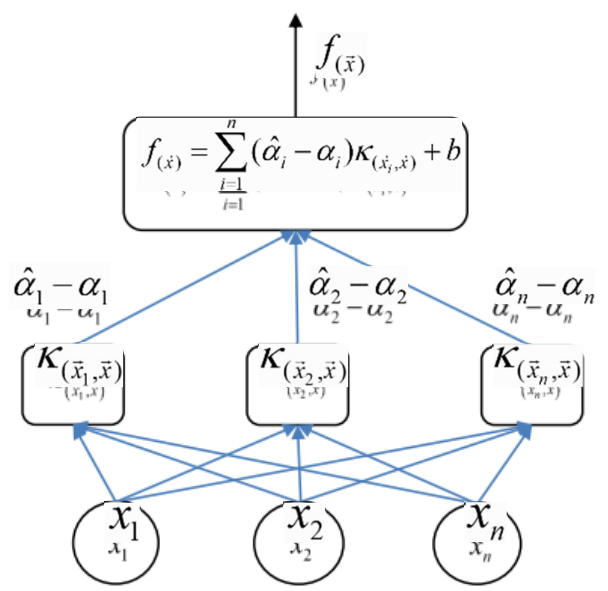

Fig 3. Support Vector Machine Structure Diagram (1)

Support vector machine can be expressed as Equation

$$
f_{(\vec{x})}=\sum_{i=1}^{n}\left(\hat{\alpha}_{i}-\alpha_{i}\right) \kappa_{\left(\vec{x}_{i}, \vec{x}\right)}+b
$$

Support vector in support vector machine (SVM) is the nearest series of points to hyperplane in the sample. The minimum distance between these points and hyperplane is the core problem to determine the hyperplane position. When the support vector machine is used for prediction, the model can predict the results according to a series of new input parameters, that is, to calculate new prediction points on both sides of the hyperplane. After combining kernel method, support vector machine can also deal with the problem of complex nonlinear relationship containing many influencing factors.

\subsection{Example Calculation and Comparison}

The training statement svmtrain (c, b, '-s-t-c-g-p') is used to train the model with support vector machine in Matlab, and the selection of parameters $-\mathrm{s},-\mathrm{t},-\mathrm{c},-\mathrm{g}$, - $\mathrm{p}$ will affect the prediction accuracy of the model.

The range of $-\mathrm{s}$ is $[0,4]$ integer, where 0 and 1 are classified, and 2,3 and 4 are regression prediction. $-\mathrm{t}$ is the type of kernel function. After testing, this paper selects the radial basis kernel function, as shown in Equation (2).

$$
\kappa_{\left(\vec{x}_{i}, \vec{x}\right)}=\exp \left(-r\left\|\vec{x}_{i}-\vec{x}\right\|^{2}\right)
$$

Where $-r$ is the inverse of-g.

In this paper, the grid method is selected to optimize the parameters of support vector machine. However, the grid method needs to traverse each point within the specified grid range, and the grid point with the smallest error is selected as the optimal parameter of support vector machine. If the optimal parameter is found in a larger range, the calculation time will be prolonged. The parameters in the model are shown in Table 4.

Table4. Support vector machine parameters

\begin{tabular}{|c|c|c|c|c|c|}
\hline $\begin{array}{c}\text { Para- } \\
\text { meter }\end{array}$ & $-\mathrm{s}$ & $-\mathrm{t}$ & $-\mathrm{c}$ & $-\mathrm{g}$ & $-\mathrm{p}$ \\
\hline $\begin{array}{c}\text { Func- } \\
\text { tion }\end{array}$ & SVM & $\begin{array}{c}\text { Type } \\
\text { kernel } \\
\text { func- } \\
\text { tion } \\
\text { type }\end{array}$ & $\begin{array}{c}\text { Loss } \\
\text { func- } \\
\text { tion }\end{array}$ & $\begin{array}{c}\text { Kernel } \\
\text { gamma } \\
\text { func- } \\
\text { tion }\end{array}$ & $\begin{array}{c}\text { Loss } \\
\text { func- } \\
\text { tion }\end{array}$ \\
\hline $\begin{array}{l}\text { Taking } \\
\text { values }\end{array}$ & 4 & 2 & 2.2 & 2.8 & 0.01 \\
\hline $\begin{array}{l}\text { Impli- } \\
\text { cation }\end{array}$ & $\mathrm{v}-\mathrm{SVR}$ & $\begin{array}{c}\text { kernel } \\
\text { function }\end{array}$ & $\begin{array}{c}\text { RBF } \\
\text { kernel } \\
\text { func- } \\
\text { tion } \\
\text { para- } \\
\text { meters }\end{array}$ & $\begin{array}{c}\text { RBF } \\
\text { kernel } \\
\text { func- } \\
\text { tion } \\
\text { para- } \\
\text { meters }\end{array}$ & v-SVR \\
para \\
-meters
\end{tabular}

The obtained parameters are substituted into formula (1) (2) to obtain the model Equation (3) as follows.

$$
f_{(x)}=\sum_{i=1}^{29}\left(\hat{\alpha}_{i}-\alpha_{i}\right) \exp \left(-2.8\left|x-x_{i}\right|^{2}\right)+0.239841
$$

The model has 29 support vectors as shown in Table 5 .

Table5. Support vector in support vector machine prediction model

\begin{tabular}{|c|c|c|c|}
\hline Number & $\hat{\alpha}_{i}-\alpha_{i}$ & Number & $\hat{\alpha}_{i}-\alpha_{i}$ \\
\hline 1 & -0.2209 & 16 & -0.3812 \\
\hline 2 & 0.7966 & 17 & -1.6022 \\
\hline 3 & -2.2 & 18 & 1.2484 \\
\hline 4 & 1.3263 & 19 & 2.2 \\
\hline 5 & -0.8827 & 20 & -2.2 \\
\hline 6 & 0.2597 & 21 & 0.8606 \\
\hline 7 & -0.1203 & 22 & 2.2 \\
\hline 8 & -0.2547 & 23 & -1.6435 \\
\hline 9 & 0.2310 & 24 & 0.2455 \\
\hline 10 & 0.2942 & 25 & -0.2826 \\
\hline 11 & -2.2 & 26 & 0.1832 \\
\hline 12 & 1.0564 & 27 & 0.1562 \\
\hline 13 & -0.3896 & 28 & 0.1642 \\
\hline 14 & 0.0302 & 29 & 1.3516 \\
\hline 15 & -0.2263 & & \\
\hline & & & \\
\hline
\end{tabular}

Absolute error and relative error of modeling and predicting results are shown in Table 6. 
Table6. Support Vector Machine prediction absolute error and relative error

\begin{tabular}{|c|c|c|c|c|}
\hline \multirow{2}{*}{ Number } & \multicolumn{2}{|c|}{$\begin{array}{c}\text { Wax deposition velocity } \\
\left(\mathrm{g} /\left(\mathrm{m}^{2} \cdot \mathrm{h}\right)\right.\end{array}$} & \multirow{2}{*}{$\begin{array}{c}\text { Relative } \\
\text { error } \\
(\%)\end{array}$} & $\begin{array}{c}\text { Absolute } \\
\text { error } \\
(\%)\end{array}$ \\
\cline { 2 - 3 } & $\begin{array}{c}\text { Experimental } \\
\text { value }\end{array}$ & $\begin{array}{c}\text { Predicted } \\
\text { value }\end{array}$ & & \\
\hline 1 & 8.66 & 9.17 & 5.92 & 0.51 \\
\hline 2 & 8.33 & 8.05 & 3.40 & 0.28 \\
\hline 3 & 8.12 & 7.29 & 10.22 & 0.83 \\
\hline 4 & 7.86 & 7.23 & 8.01 & 0.63 \\
\hline 5 & 18.09 & 15.65 & 13.49 & 2.44 \\
\hline 6 & 11.3 & 10.31 & 8.73 & 0.99 \\
\hline 7 & 22.46 & 15.38 & 31.54 & 7.08 \\
\hline 8 & 16.43 & 12.06 & 26.58 & 4.37 \\
\hline
\end{tabular}

It can be seen from Table 7 that the maximum relative error, the minimum relative error and the average relative error of the eight groups of data in the prediction group calculated by the support vector machine model are $31.54 \%, 3.40 \%$ and $13.49 \%$, respectively, which are all smaller than the prediction error of the RBF neural network. This model has the feasibility of predicting wax deposition rate, and has an expression, which can be calculated by using the formula after training.

\section{Conclusions}

From the perspective of error, both the RBF neural network model and the support vector machine model can predict the wax deposition rate of crude oil pipelines. The calculation errors of the support vector machine model are slightly lower than those of the RBF neural network, but the errors are not much different, because the number of samples required by the support vector machine is less than that of the neural network. Under the condition of limited samples, the accuracy of support vector machine is higher than that of neural network.

\section{Acknowledgments}

This paper is one of the periodical achievements of Dezhou's Key Laboratory of High-efficiency Heat Pump Air Conditioning Equipment and System Energy Saving Technology (Item Number:26).

\section{References}

1. Wang Ping, Jiang Guoye, Tian Yibing, Wang Hongxia, Shao Yingwu, Wu Ming. The Effect of Wax Thickness on Oil Transportation Cost[J]. Journal of Petroleum and Chemical Universities, 2002 (01): 4750.

2. Wang Yining, Song Jiaxi, Yang Ning, Zhang Heng, Fengyang. Calculation and Field Application of Reasonable Number of Shots in Well Site[J]. China Petroleum and Chemical Standards and Quality, 2021,41 (02): 136-139.

3. Zhang Zaixiao, Huang Qiyu, Zhang Xun, Dan Jinxu, Zhu Xiangrui, Zhang Yu. Simulation Analysis of Wax Deposition Law of Crude Oil in Submarine Pipeline of Liuhua 16-2 Oilfield[J]. Offshore Oil and Gas in China, 2020, 32(06): 172-178.

4. Ge Yun. Study on Wax Deposition Model of Waxy Crude Oil Pipeline[D]. Southwest Petroleum University, 2014.

5. Gu Lei, Siong Tok D K, Yu Ding-li. Development of Adaptivep-step RBF Network Model with Reccursive Orthogonal Least Squares Training[J]. Neural Computing and Applications, 2018, 29(5): 1445-1454.

6. Wang Xueliang. Prediction and Analysis of Wax Deposition in Pipeline Crude Oil in Wang Xueliang Huachi Area[D].Xi' an : $\mathrm{Xi}^{\prime}$ an University of Petroleum, 2010.

7. Chu Xin. Study on Heat Transfer Law of Wood Based on Neural Network[D]. Shandong Jianzhu University, 2020 . 